\title{
News
}

\section{THE ECONOMIC CRISIS AND INFECTIOUS DISEASE CONTROL}

\author{
M Suhrcke (m.suhrcke@uea.ac.uk)1,2, M McKee²,3, D Stuckler ${ }^{2,4}$, J E Suk ${ }^{5}$, S Tsolova ${ }^{5}$, J C Semenza ${ }^{5}$ \\ 1. University of East Anglia, United Kingdom \\ 2. London School of Hygiene \& Tropical Medicine, United Kingdom \\ 3. European Observatory on Health Systems and Policies, Belgium \\ 4. University of Oxford, United Kingdom \\ 5. Future Threats and Determinants Section, Scientific Advice Unit, European Centre for Disease Prevention and Control, Sweden
}

This article was published on 12 November 2009.

Citation style for this article: Suhrcke M, McKee M, Stuckler D, Suk JE, Tsolova S, Semenza JC. The economic crisis and infectious disease control. Euro Surveill. 2009;14(45):pii=19401. Available online: http://www.eurosurveillance.org/ViewArticle.aspx?ArticleId=19401

The economic crisis has challenged many deeply held notions about banks, markets and the financial sector. Concerns have also been raised that the economic crisis has the potential to affect the control of infectious diseases. Although there is agreement that the crisis will affect infectious disease control, there is disagreement about how. Some scientists have raised concerns that both emerging infectious disease threats, such as the H1N1 pandemic, as well as longstanding challenges, such as control of tuberculosis, HIV/AIDS and their drug-resistance strains, could suffer if communicable disease control budgets are cut. They point to the rises in HIV/AIDS and tuberculosis that occurred in former communist countries in the 1990s.

Thus far, evidence on the effects of crisis on infectious diseases in general is limited. As the current crisis unfolds, it will be crucial to continue the work with identifying emerging infectious disease risks and control them rapidly before they develop into populationwide threats.

How the economic crisis is impacting on communicable disease surveillance and control in European Union (EU) and European Free Trade Association (EFTA) countries is the subject of a study being undertaken by European Centre for Disease Prevention and Control (ECDC) in collaboration with a team from the University of East Anglia and the London School of Hygiene \& Tropical Medicine.

In order to help us gather data, please complete a short on-line questionnaire available at: http://www.surveymonkey.com/s.aspx?s $\mathrm{m}=$ SoCRzEG2oYgZOoNCDH8G_2bQ_3d_3d

This should take no more than 30 minutes of your time. It is important to gather as much relevant information as possible so any assistance you can provide in answering this questionnaire will be extremely valuable. All responses will, of course, be treated as confidential but if you permit we may come back to you with questions for clarification of points that arise.

If you have any questions, please contact Sandra Alves (email: Sandra.Alves@ecdc.europa.eu). 